\title{
Scientific research groups' cooperation with firms and government agencies: Motivations and barriers
}

Authors: Irene Ramos-Vielba ${ }^{\mathrm{a}} \cdot$ Mabel Sánchez-Barrioluengo ${ }^{\mathrm{b}^{*}} \cdot$ Richard Woolley $^{\mathrm{b}}$

\footnotetext{
${ }^{\text {a }}$ I. Ramos-Vielba

Forschungsinstitut für Arbeit, Technik und Kultur e.V. (F.A.T.K.), Universität Tübingen

Address: Haußerstraße 43, 72076 Tübingen (Germany)

${ }^{b}$ I. Ramos-Vielba $\cdot$ M. Sánchez-Barrioluengo $\cdot$ R. Woolley INGENIO (CSIC-UPV) Universitat Politècnica de València

Address: Ciudad Politécnica de la Innovación, Edif 8E 4º, Camino de Vera s/n, 46022 Valencia (Spain)

* M. Sánchez-Barrioluengo $(\square)$

e-mail: msbarrioluengo@ingenio.upv.es, phone number: +34 963877048, fax: +34 963877991
} 


\title{
Scientific research groups' cooperation with firms and government agencies: Motivations and barriers
}

\begin{abstract}
The behavior of academic researchers who engage in cooperation with industrial partners has already been the subject of considerable research. A lack of understanding exists regarding the motivations of scientific research groups to engage in cooperation with other types of external non-academic organizations and the perceived barriers that may inhibit this activity. In this paper we analyse the motivations and perceptions of risks that shape scientific research groups' cooperation with industry and government partners. We find that motivations to cooperate are partly dependent on the type of partner organization involved, with advancing research goals mainly acting as an inducement to cooperate with government agencies, while searching for opportunities to apply knowledge motivates partnerships with firms. We also find that the majority of research groups cooperate with both firms and government, with their major motivation being to apply their knowledge. Among research groups that only cooperate with firms, interaction effects between motivations influence the likelihood of cooperation. Research groups do not consider risk to scientific autonomy a barrier to cooperating with firms, while risk to scientific credibility inhibits cooperation independently of the type of external partner. However, being motivated to advance research can reduce the effect of perceived barriers, independent of the type of partner organisation.
\end{abstract}

Keywords: Motivations $\cdot$ Barriers $\cdot$ Research groups $\cdot$ Cooperation $\cdot$ Knowledge transfer $\cdot$ External partner organizations

JEL Classification $\quad \mathrm{O} 32 \cdot \mathrm{O} 33 \cdot \mathrm{O} 34 \cdot \mathrm{O} 38$ 


\section{Introduction}

Public sector research organizations (PSROs), including universities and research institutes, are driven to cooperate with external private and public sector partners by a variety of factors. These factors include external demands for new knowledge (Meyer-Krahmer and Schmoch 1998; Schartinger 2002) as well as the need for financing (OECD 1999; Santoro and Gopalakrishnan 2000), and can generate interdependent relationships (Geisler 1995). Despite the volume of work done on cooperation patterns among scientific researchers (see the benchmark study of Katz and Martin (1997) and the recent review by Bozeman et al. (2013)), new aspects of cooperation need to be examined and there is considerable work remaining. This paper seeks to contribute to the cooperation literature by analysing whether scientists are driven by distinct sets of motivations, or perceive different barriers, depending on whether the external cooperation partner is a private firm or a government agency (public).

The understanding of factors that may contribute to boosting links between researchers and external partners and, precisely, what binds different agents together remains limited (D'Este and Patel 2007; Lam 2011; D'Este and Perkmann 2011). This is despite the recognition that these factors are keys to a better understanding of the dynamic of knowledge transfer practices and relations (Bozeman et al. 2013). In this respect, the types and patterns of interactions between research organizations and their cooperative partners do not appear to assume a single typical overall form or set of arrangements (Thune 2007). Improved information is desirable in order to better assess the effects produced by current policies designed to facilitate cooperation between PSROs and the end-users of research (Turpin and Fernández-Esquinas 2011; Woolgar 2007). However, the majority of the literature focuses on the analyses of cooperation in terms of university-industry relationships (Powell et al. 1996; Landry et al. 2007; D'Este and Perkmann 2011; Tartari and Breschi 2012; Dornbusch and Neuhäusler 2015), overlooking a wider variety of external agents that can be involved in the process of cooperation. In this respect, the value added of this work is the understanding of the underlying factors that contribute to increase/decrease cooperative relationships and the differences that appear when this cooperation is conducted with different types of external partner organizations in both the private and public sectors.

A second limitation of the current literature relates to how motivations and barriers affect each other. Most analyses assume that specific types of motivations have an independent effect on external cooperation activity. There has been no analysis to date of whether motivations are intertwined and how they might influence each other. Whilst researchers may be motivated by intellectual curiosity and by the desire to solve social problems, for example, there have been no analyses of whether being strongly motivated intellectually may also influence social motivations or vice versa. This is something of an oversight, given that researchers embrace multiple modes of external cooperation (Bozeman et al. 2013; Chompalov et al. 2002). In other words, many researchers' are engaged in a range of cooperative activities, which are likely to be underpinned by the co-existence of multiple motivations. A contribution of this paper will be to analyse the interactions of different motivating factors to discover whether such interactions may also impact on the propensity to cooperate with different types of external partner organization. With notable exceptions, the current literature also tends to treat motivations and barriers separately. Yet, it seems highly likely that being strongly motivated to cooperate may reduce the perceived importance of certain barriers 
(Tartari and Breschi 2012). To complement this study, the paper thus also analyses the interactions between motivations cooperate and perceived barriers to see whether strong motivations can play a role in reducing the effect of barriers to cooperate with different external partners.

Three research questions are addressed in this study. First, we investigate what motivates PSRO researchers to cooperate with external partners and identify the coexisting perceptions of barriers that may be preventing or restricting cooperative relationships. Second, we assess the impact of researchers' motivations and perceptions of barriers into the propensity to cooperate with different type of partner organization. Third, we ask whether interactions between different motivations, and between motivations and barriers, can impact on the propensity to cooperate with different types of partner organizations. The following section reviews literature about cooperation activities and the motives for and barriers to involvement in these relationships. Section 3 specifies the methodological approach, the main variables and the analyses conducted, with results described in Section 4. Finally, Section 5 includes a discussion of the findings and proposes some policy implications of the study.

\section{Cooperation or non-cooperation: that is the question.}

\subsection{Cooperation: why, how and with whom?}

According to a traditional model most often associated with Polanyi (1962) and Merton (1973), diverging logics can characterize cooperation relationships between researchers and external partners. On the one hand, public sector scientists' decisions reflect and are shaped by a reputation-based scientific reward system (Merton 1973). On the other hand, private firms are guided by the imperative of producing tradable results (Dasgupta and David 1994), whilst ensuring that overall benefits exceed the costs of cooperation (Bolli and Woerter 2013) and that revenue increases while R\&D costs - at worst - increase by a smaller proportion (Leyden and Link 2013). In this model, a fundamental tension exists between maintaining an individually-directed scientific career trajectory and participating in cooperatively-directed external research partnerships, even though these partnerships may potentially contribute to both the social relevance and resource base of a PSRO.

In contrast to a traditional model, Owen-Smith and Powell (2001: 4) argue that contemporary researchers are required to respond to a broader set of institutional expectations, including entrepreneurial engagement, which has 'created a myriad of positions that are neither old nor new school, but instead combine characteristics of both'. In this view, academics are increasingly required to conduct and manage an evergrowing 'portfolio' of research activities. The broadening of university missions (Sánchez-Barrioluengo, 2014) and the 'increased susceptibility of academic activity to both market forces and social expectations' (Organ and Cunningham 2011), may push researchers towards cooperative activities with other organizations (Tartariet al. 2012). In another alternative model, Boschma (2005) describes a multi-dimensional concept of 'proximities' (cognitive, organizational, social, institutional, geographical) as shaping the propensities for innovation system actors to cooperate and learn from each other. From this perspective too much proximity (path dependence and lock-in) is equally as problematic for innovation as too little proximity (isolation). From the perspective of this paper, of particular interest is the openness of PSRO research groups to cooperate 
with multiple types of external partner organisations. Working with different types of non-academic partners could be important for avoiding the kinds of systemic 'overcoordination' problems Boschma (2005) describes, which may be less likely to occur when cooperation and learning takes place with partner organisations of different types.

The behaviour of academic researchers who engage in cooperation with industrial partners has already been the subject of considerable research (Bozeman et al. 2013; Perkmann et al. 2013). In fact, most studies of cooperation focus on university-industry relations, particularly academic entrepreneurship initiatives and commercialization efforts (Perkmann et al. 2013). What Bozeman and colleagues (2013) categorise as studies of 'property focused' research collaborations, either focus on increments to knowledge measured by articles produced, cited and, more rarely, demonstrably used, or focus on increments to wealth measured by patents, new technology, new business, start-ups and, more rarely, profits. This literature also highlights that collaborations with industry are shaped by the characteristics of scientific disciplines and some differences emerge between them in terms of both frequency of cooperation and mechanisms though which the relationship is established. Powell et al. (1996) and D'Este and Perkmann (2011) demonstrate the importance of cooperation with the private sector in life sciences and the physical and engineering sciences respectively, while Tartari and Breschi (2012) conclude that basic disciplines being less likely to cooperate with industry compared to applied disciplines such as engineering. Differences have also been observed in terms of knowledge transfer within natural sciences and engineering, with certain disciplines more active than others (Landry et al. 2007). Tartari and colleagues (2012) investigate peer effects on university academics behaviour in engaging with industry in the UK, using social psychology to underpin the hypothesis that peers tend to emulate each other in this regard. They find that lowerranked scientists are influenced by the behaviour of their peers in the immediate social environment. Whilst they find that 'basic disciplines' (mathematics, chemistry and physics) are negatively correlated to working with industry, overall it is apparent that organizational units with a peer culture of cooperating with industry are likely to influence positively the cooperation behaviour of new or junior researchers.

Another main difference appears in terms of the mechanism used in the process of knowledge transfer. In this case, disciplinary affiliation has also been found to affect the specific knowledge transfer channel researchers select for their interchanges with industry (Bekkers and Bodas Freitas 2008; Martinelli et al. 2008; Perkmann et al. 2013). Other studies conclude that there is strong variation in patenting rates between scientific discipline (Agrawal and Henderson 2002). Science, technology, engineering and mathematics (STEM) fields and social science and humanities (SSH) have also been found to engage in different types of knowledge transfer practices with industry partners (Olmos Peñuela et al. 2013). These authors also argue that differences between STEM and SSH are also related to the types of non-academic actors with whom researchers collaborate. While STEM researchers tend to engage with firms, SSH researchers' cooperation partners are more diverse, including the public and voluntary sectors as well as through direct engagement with the public.

The common limitation of these studies is that they focus on the private sector as the main agent with which researchers engage in cooperation activities. This paper expands the scope of studies of cooperation by including interactions with both public and private sector partner organizations. 
2.2 Motivations and barriers for cooperation with external partners

The existence of a motivation to cooperate externally may be stifled by perceived conflicts with the pursuit of individual scientific goals. A major limit to cooperation with external partners may thus lie in tensions between different motivations for conducting research. According, the driving forces behind researchers' motivations to cooperate can be expected to be multiple, mingled, heterogeneous and conflicting (Bozeman et al. 2013). This section describes evidence about whether scientists are driven by distinct sets of motivations, or confront different barriers, regarding cooperating with external agents.

Industrial cooperation can provide an opportunity to address dual challenges: accessing resources to continue future research activities and finding solutions to real problems. Some studies show that industry tends to partner with universities closer to basis or 'new' science phase (Hall, Link and Scott 2003). Others show that inventions stemming from academic and industry collaboration can influence future technological paths, including the innovativeness of small and medium enterprises (SMEs) (Dornbusch and Neuhäusler 2015), or that collaboration on both basic research and applied technological problems can allow firms to capture positive externalities generated by PSROs and universities (Belderbos et al. 2015). However, industrial cooperation relationships may encounter real difficulties due to the 'cultural differences' that have been shown to exist between academic and industrial environments (Siegel et al. 2003; Cunningham and Harney 2006), and profound cultural differences that can generate conflict, 'since 'values' are addressed as socially shared cognitive representations of institutional goals and demands' (Rokeach, 1979: 50; cited in Dolfsma and Verburg 2008: 1040).

Lam (2011) uses scientists' value orientation regarding the interrelation of science and society to analyse their attitudes toward working with industry partners. Being motivated by extrinsic rewards is associated with an academic value orientation that is relatively strongly differentiated from business concerns. Being motivated by intrinsic rewards such as problem-solving is associated with a relatively lower differentiation of science from societal concerns. What Lam (2011) terms 'puzzle' is the intrinsic reward of discovery and curiosity driven research, whilst 'ribbon' refers to a relatively Mertonian form of extrinsic reward focused on solving research questions. These contrast with entrepreneurial scientists for whom combinations of curiosity and 'gold' (economic compensation) are important. In fact, Lam finds that half the scientists are 'hybrids' (2011: 1355) who 'maintain a firm commitment to the core scientific values', but also see the benefit of commercial engagement for their professional goals. These hybrid researchers are intrinsically motivated to cooperate externally in terms of satisfying their curiosity and making a contribution to society. It seems clear that alongside the extrinsic rewards of the ribbon, scientists can also be strongly intrinsically motivated in their commercial endeavours. Whilst this study deals with STEM disciplines only, it points out the multiplicity of both the goals and the motivations that individual scientists embrace (Owen-Smith and Powell 2001), highlighting the different configurations of these goals and motivations that appear to be associated with different cooperation activities.

Perkmann and colleagues (2013) found that whilst attracting resources, obtaining knowledge, or building social capital are the main general logics underpinning cooperation, involvement in commercialisation activities is more 
connected to interest in the exploitation of a specific technology and to obtaining an economic reward. D'Este and Perkmann (2011) found that academics are motivated to cooperate with industry primarily by the opportunities such cooperation affords to support their academic research work. Motivations are also dependent on the channel of engagement with industry, with patenting motivated by commercialization and other cooperative activities motivated by opportunities for new learning processes in addition to acquiring funding (Meyer-Krahmer and Schmoch 1998; D'Este and Perkmann 2011). Motivations for external cooperation are thus likely to depend on a range of individual and contextual factors.

At the same time, the literature also highlights researchers' concerns that the processes of cooperating with private industry can be detrimental to academic research (Slaughter and Rhoades 1996; Nelson 2001; Geuna and Nesta 2006). These concerns revolve mainly around the problems of secrecy and skewing (Florida and Cohen 1999). The secrecy problem refers to the extent to which an increasing degree of cooperation with industry is associated with restrictions on the disclosure and dissemination of research findings contrary to the norms of open science. The skewing problem refers to the possibility that a greater emphasis on cooperation with industry could skew scientists' activities away from a curiosity-driven academic research agenda. Empirical studies have confirmed that a major concern of academic researchers is the potential for external co-operations with private industry to have a negative impact on their freedom to pursue a relatively autonomous research agenda (D'Este and Perkmann 2011; Lee 1996). This concern is mirrored from an industry perspective, with intellectual property rights (IPR) problems regarding university collaboration being an apparently insurmountable barrier in some cases (Hall, Link and Scott 2001). These concerns can be ameliorated in the case of large research joint ventures (RJV) where the addition of a university is less likely to create additional appropriation problems compared to a small RJV (Link and Scott 2005), while entrepreneurial start-ups may find collaborating with universities less risky with regard to IPR than incumbent market occupants (Leyden and Link (2013).

Tartari and colleagues describe the traditional concerns of academics regarding autonomy and freedom of information circulation as 'orientation barriers' to cooperating with industry (2012: 657-8). In addition, they identify 'transactional barriers' associated with the burdens of bureaucratic knowledge transfer and commercialization processes (2012: 658-9). The impact of these factors is mediated by researchers' prior experience of industry cooperation and the amount of trust they have in these partners. Tartari and Breschi (2012) identify the potential to acquire resources as a key motivator cooperating which can overcome Mertonian-type barriers regarding risks to academic freedom and the openness of results. This study highlights the fact that strong motivations may have the effect of reducing barriers to industrial cooperation.

In summary, previous literature has focused on the analysis of the factors underpinning motivations and barriers related to cooperation with firms. The shortcomings of this literature are twofold. First, whilst there is a growing body of evidence regarding motivations to cooperate with industry, this is not the case regarding motivations to cooperate with other types of external partners. There is also a concomitant lack of understanding about barriers to cooperating with external partners other than industry. Second, very limited work has considered motivations and barriers 
as not existing in isolation, but as a spectrum of positive and negative factors influencing researchers' propensity to cooperate externally. This paper contributes to filling these gaps, by asking the following questions. What are the underlying factors which motivate or hinder researchers' cooperation with different types of external partners? What is the effect of researchers' having multiple motivations to cooperate? To what extent does the presence of motivations decrease the effect of barriers?

\section{Methodological approach}

\subsection{Research groups as unit of analysis}

Research groups ${ }^{1}$ are key knowledge producing organizations within national science systems (Rey Rocha et al., 2008) and a relevant unit of reference when R\&D performance is evaluated (Larédo and Mustar 2001). Research groups are the fundamental collective unit of much scientific activity and their characteristics may have an important bearing on the motivations and barriers to cooperation with external partners, including both structural and functional factors (Martin-Sempere et al. 2002; Adams et al. 2005; S. Lee and Bozeman 2005). However, little is understood about how groups' motivations and barriers may impact on a research groups' propensity to cooperate with external partners. Due to the difficulty of questioning all members of a research group, in this study research group leaders' opinions were taken as a proxy for the research group in terms of perceived motivations and barriers. Research group leaders were considered to be the best choice, not only because they may act as influential role models among co-workers (Bercovitz and Feldman 2008), but also because they are well-informed about individual research careers and strategies and about the portfolio of external cooperation activities in which the research group is involved.

Research groups in PSROs in Spain are primarily located in universities and the centres of the Spanish National Research Council (CSIC), along with some Institutes directly funded by national and regional governments. The higher education sector includes 73 universities, of which 48 are public and 25 private. CSIC is the largest single research institution in the country, employing more than five thousand researchers. Table 1 summarizes their contribution - in terms of expenditure and human capital - within the Spanish R\&D system: between them, universities and the CSIC account for almost $34 \%$ of $R \& D$ expenditure and approximately $54 \%$ of full time equivalent (FTE) researchers in Spain. In this study we use the research group as a transversal unit of analysis common to all PSROs.

\section{[Insert Table 1 about here]}

\subsection{Survey and sample}

The core of the study is a survey among the heads of the research groups as representers of the general experiences of the research team. The survey was structured

\footnotetext{
${ }^{1}$ In our study we consider a research group that which works as a stable team, usually consisting of one leader and several researchers at different stages in their professional careers. Team members share goals, resources and research activities.
} 
in five sets of questions: interviewee profile; research group characteristics; relationships between the research group and other agents in the innovation system; detail on cooperation with firms; and evaluationg of the regional context for cross-sector cooperation with non-academic organizations. The survey was self-completed online with telephone reinforcement. This paper focuses on the second and third parts of the survey to develop its analysis.

The population consisted of active research groups in PSROs in Spain, following official sources in four regions with different scientific and technological profiles Andalusia, the Basque Country, the Canary Islands and Madrid (Ramos-Vielba 2011). Through a quota sampling method from a census survey, we obtained a final sample of 851 research groups weighted according to the total number of research groups in each of the four regions. The survey was targeted at research group leaders, focusing on these scientists' perceptions about external cooperation and was conducted in OctoberDecember 2011. It achieved a representative response by region with a total sample error of $\pm 3.2 \%{ }^{2}$.

\subsection{Main variables}

The survey included two questions about motivations for (11 categories), and barriers to ( 7 categories) cooperation. The importance of motivations for cooperation were measured using Likert-type scales from 1=not important to $4=$ =particularly important. The significance of barriers to cooperation were measured using Likert-type scales ranging from $1=$ never to $5=$ =always. The study encompases two types of dependent variables. First, a binary variable, cooperation, that refers to the general involvement of research groups with non-academic organizations and takes the value 1 if the research group has cooperated and 0 otherwise. We specified cooperation as a broad range of interactions including: consultancy work; contract research agreement (financed exclusively by the external partner); joint research agreement (shared financing or with public support); renting of facilities, materials or equipment; exploitation of a patent or utility model or joint patents; training of postgraduates and internships at the partners' sites; temporary exchange of scientific and technical personnel; specific training of external workers by the PSROs; participation in a joint venture of hybrid research center; creation of a new firm (spin-offs and start-ups); informal cooperative relations; knowledge dissemination activities. Second, a nominal variable includes information about the external partner involved. This variable includes four categories: no cooperation; cooperation only with firms, cooperation only with government agencies; and cooperation with both firms and government. Government was defined as non-academic public sector organisations such as government ministries, departments or other statutory authorities, at all levels of government (European, national, regional, local). The major PSROs (CSIC, National Institutes and universities) are excluded from this category. Cooperation with external partners thus does not include cooperation between research groups in different PSROs in this study. Independent variables include motivations for and barriers to cooperation, built with the mean value of each factor resulting from the factor analysis (explained below). We also incorporate a set of control variables in order to avoid problems related to cross-

\footnotetext{
${ }^{2}$ The error for each region was: Andalusia, $\pm 6.1 \%$; Madrid, $\pm 5.2 \%$; Canary Island, $\pm 6.8 \%$; and Basque Country, $\pm 6.3 \%$.
} 
sectional studies, which comprise some research group characteristics (size, age, type of

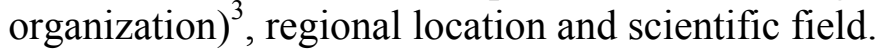

Among these control variables, the size of the research group is measured as the total number of personnel in the group, including tenured researchers, contracted researchers, technical staff and $\mathrm{PhD}$ students. For this quantitative variable we checked normality using the Kolmogorov-Smirnov test. Given a significant result, we explored the variable normalization applying a QQ-plot graph and decided to use the log transformed variable (ln) in our analysis. The age of the research group is a dichotomous variable with the value 0 if the group has existed from 0-10 years and 1 if it has existed for more than ten years. This can be interpreted as a proxy to control for emergent or consolidated groups. Type of organization distinguishes between those research groups situated within the CSIC (value 0) or in a university (value 1). Region controls for the location of the research group. Scientific field covers four categories: Physical Sciences (Biology and Biotechnology, Agrifood, Experimental Sciences); Health; Social Sciences and Humanities; and ICT and Environmental Sciences (Technology, Natural Resources Energy and Environment, Information and Communication Technology).

Annex I displays the correlation matrix between the independent variables. Low values show the acceptability of including these variables in the model. The highest correlation appears between two motives: conditions for research and knowledge application and engagement (0.56). To test if this result implies a real problem, Annex I also reports the tolerance statistics values, indicating whether an independent variable has a stronger linear relationship with another independent variable. As shown, all the tolerance statistic values are much higher than 0.2 , which ensures that no multicollinearity problems arise in the regression model.

\subsection{Process details}

The methodology used in this work includes four types of analysis. First, a factor analysis based on principal components with Kaiser normalization was performed in relation to both motivations and barriers for cooperation. The purpose was not only to discover the factors that define researchers' assessment of cooperative relations, but also to identify differences in the patterns of cooperation among different fields. Second, in order to analyse factors influencing cooperation with external actors, we carry out two types of regressions: logistic and multinomial. The former allows the identification of general involvement of research groups with external partners and uses as a dependent variable the dummy 'cooperation'. The latter is necessary because the variable in relation to the type of cooperation partner includes mutually-exclusive nominal and unordered values (McFadden 1974). In this case no-cooperation is our reference category. Third, in order to complement the second phase, we compute the three-way interaction between motivations in order to understand if having a wider spectrum of motivations influences cooperation with different external agents. We use a step-wise strategy which means the introduction of: 1) control variables (baseline model); 2) the

\footnotetext{
${ }^{3}$ Although researchers working at CSIC or universities are part of PSROs, Teirlinck and Spithoven (2012) suggest distinguishing between public research institutes and universities due to their particularities in terms of research orientation (development and applied research versus basic research), research facilities (related to scale and complexity) and the management of research.
} 
main effects of the independent variables; and 3) the two-way interactions and 4) the three-way interaction terms. To demonstrate the importance of the combination of different motivations simultaneously, results would require significant increases in variance explained $(\Delta \mathrm{R} 2)$ with the addition of the two-way and three-way interactions (Shalley et al. 2009). Finally, a more exhaustive analysis of motivations is conducted in order to understand to what extent barriers to cooperate could be attenuated by motivational factors. To do this, we analyse the interaction terms between motivations and barriers using dummy variables for motivations that take the value 1 if the research group gives high importance to a particular motivation (i.e. greater than the average) and 0 otherwise (barrier variables maintain the values from previous analysis).

\section{Results}

\subsection{Research group characteristics}

Table 2 shows descriptive statistics for research group characteristics. The majority of them are part of universities (74\%) and are located mainly in Madrid (38.9\%) and Andalusia (26.7\%). More than half of the groups have existed for longer than a decade. On average they are composed of 10 people, with the smallest group having two people and the largest 68 . The distribution of research groups by scientific fields is: $34.7 \%$ Physical Sciences; $13.2 \%$ Health; 31.4\% Social Sciences and Humanities (SSH); and 20.8\% ICT and Environmental Sciences (ICT\&E).

\section{[Insert Table 2 about here]}

\subsection{Cooperation by type of partner organization}

Our results suggest that research groups give high importance to external cooperation, because $89.5 \%$ have participated in some cooperative activity (Figure 1 left graph), with $75.7 \%$ of the research groups cooperating with government agencies and $68 \%$ with firms. However, most research groups (55.7\%) cooperate with both types of external partner, while just $12.3 \%$ had linkages only with firms and $20 \%$ exclusively with government partners. These results indicate a high level of cooperation with diverse partner organizations. Once again there is variation by scientific field, with research groups in Physical Sciences and ICT\&E cooperating more with firms and research groups in Health and SSH cooperating more with government agencies (Figure 1 - right graph).

\section{[Insert Figure 1 about here]}

\subsection{Motivations and barriers across scientific fields}

Results from a factor analysis show that motivations for cooperation group in three factors (total variance explained: 59.5\%): advancing research; applying knowledge; and accessing financial resources (Table 3, Panel A). Barriers to cooperation group in two clusters (total variance explained: 67.2\%): risk to scientific autonomy; and risk to scientific credibility (Table 3, Panel B). Both factor analyses explain around $60 \%$ of total variance, which can be considered a satisfactory level in social science (Hair et al. 1998). To assess the degree of consistency (reliability) we use 
Cronbach's alpha, accepting values equal to or above 0.6 as valid. Our results suggest that we can gather our items into three motivations and two barriers that impact on the cooperation of research groups with external agents.

\section{[Insert Table 3 about here]}

Using the results of factor analysis, we have created five new variables (three motivations and two barriers) as the mean value of the items within each factor (average of this new variables included in Table 4, first column). In general, applying knowledge appears to be the most important motivation for cooperation and scientific autonomy the barrier with the higher impact. Table 4 also shows significant differences in motivations and barriers when we take into account the scientific field of the research group. Variation by scientific field is evident in relation to the importance of all three motivations for cooperation. Physical Sciences research groups are less motivated by advancing research than groups in all other fields. SSH and ICT\&E groups are more strongly motivated by knowledge application than groups in the other two fields, and Health groups are more strongly motivated by accessing financial resources than are groups in all other fields. In relation to barriers to cooperation, there is significant variation between fields regarding the risk to scientific autonomy, with $\mathrm{SSH}$ research group less concerned about risks to scientific autonomy than groups in all other fields. No variation exists regarding the risk to scientific credibility, meaning research group leaders give the same relative importance to this barrier independently of the field ${ }^{4}$.

\section{[Insert Table 4 about here]}

\subsection{Motivations for and barriers to cooperation}

Table 5 and 6 show the results for the different regression carried out to analyse motivations for and barriers to cooperation between research groups and non-academic partners. The logistic regression (Model 1) analyses factors related to general cooperation patterns. Although each motivation has a positive influence on cooperation, none of these results have statistical significance. In the case of barriers, both risk to scientific autonomy and scientific credibility have a negative relationship with cooperative activities, however only the latter is significant. Among control variables, research group size has positive and significant relationships with cooperation, meaning that larger groups are more likely to cooperate.

\section{[Insert Table 5 around here]}

The lack of statistically significant results in Model 1 may be due to differences related to the type of external partner. We test the possibility that motivations for and barriers to cooperation are influenced by the type of partner organization (Model 2$)^{5}$. Model 2a includes information for the main factors. Overall, our results again suggest a

\footnotetext{
${ }^{4}$ Post-hoc results are not presented in Table 4 for space reasons.

${ }^{5}$ For space reasons results only include information for the model with main effects and the final model including three-way interaction term. Proposed models guarantee the importance of the full model because the adjusted-R2 increases in each model: baseline model, adj-R2=13\%; main effects model, adj$\mathrm{R} 2=17.3 \%$; two-way interaction model, adj-R2=18.3\%; full model, adj-R2 $=19.7 \%$.
} 
positive effect of motivations on cooperation and a negative effect of barriers, independent of the partner organization type. Positive and significant relationships exist between being motivated to advance research and cooperating with government partners and between being motivated to access financial resources and cooperation with firms. However, seeking to apply knowledge is apparently the broadest motivation for cooperation, with a positive and significant relationship existing between this motivation and both cooperation with firms and cooperation with firms and government. With regard to barriers, the results would tend to suggest that, overall, research groups consider there is a higher risk to scientific autonomy when cooperating with government, and a higher risk to scientific credibility when the cooperation is with firms. However, these coefficients are not statistically significant.

Subsequently, we analyse the effect of having a spectrum of motivations to cooperate through the three-way interaction term, with results presented in Model $2 \mathrm{~b}$. Having multiple motivations only tends to change the propensity to cooperate with private sector partners, while results are not significant for cooperation with government agencies and both partner types combined. This is not an unexpected result taking into account that, as we mentioned in the literature section, the motivations analysed in the literature are mainly based on cooperation activities with private sector. This leads us to focus on the explanation of the interaction term for the cooperation with firms. As interactions between continuous variables are not easily interpreted, we use the procedure outlined by Aiken and West (1991) to plot the high and low levels of each motivation (one standard deviation above and below the mean). We also fix barriers and control variables at mean values. Figure 2 depicts the pattern of moderated results related to the interaction between motivations for cooperation activities between research groups and private firms.

\section{[Insert Figure 2 about here]}

Figure 2 shows the variety of results that can be observed through the combination of motivations. In general, results show that depending on how a research group combines different motivations, this makes a difference to their propensity to cooperate with firms. For example, our results suggest that the highest level of cooperation with firms is observed when Motivation 3 (accessing finance) is high, but the other motivations are low. A similar result can be observed when Motivation 2 (applying knowledge) is high but the other motivations are low. In both these cases, as the motivation to advance research increases (Motivation 1) the level of cooperation with firms declines. Both applying knowledge (Motivation 2) and accessing funding (Motivation 3) thus appear to be important single motivators for cooperating with firms. However, when levels of both Motivation 2 and Motivation 3 are high, then the level of cooperation with firms rises as the motivation to advance research increases (Motivation 1). When levels of both Motivation 2 and Motivation 3 are low, then increasing the level of motivation to advance research has no effect on the level of cooperation with firms. In the case of cooperating with firms then, being motivated to advance research is only beneficial in the presence of both other motivating factors.

Finally, to understand whether perceptions of risk are attenuated in the presence of strong motivations, we modify motivations into dummy variables with the value 1 if a research group attaches high importance to a specific barrier (i.e. greater than the average) and 0 otherwise. Through the interaction term, we compare the effect of barriers taking into account the presence of motivational factors. Models 3, 4 and 5 
(Table 6) include the interaction terms to test the extent to which strong motivations influence barriers to cooperation.

\section{[Insert Table 6 around here]}

Table 6 specifies 3 models: Model 3 includes the motivation 'advancing research', Model 4 includes 'applying knowledge', and Model 5 includes 'accessing financial resources' as part of the interaction terms with the two barriers. The results of Model 3 suggest that those research groups motivated by advancing their scientific research are not likely to be deterred from cooperation by the risk of losing scientific autonomy, independent of the type of cooperation partner. However, research groups motivated by scientific advance are liable to be deterred by perceived risk to scientific credibility when the cooperation partner is a firm. In relation to the motivations to apply knowledge and to access financial resources, the interaction effects do not produce any significant results. The results for the motivations for, and barriers to, cooperation with each of the different types of partner organizations, are similar to those without the interaction terms included (Table 5).

\section{Discussion and policy implications}

\subsection{Discussion}

The behaviour of academic researchers who engage in cooperation with industrial partners has already been the subject of quite extensive research (Katz and Martin 1997; Bozeman et al. 2013; Perkmann et al. 2013). However, whether scientists are driven by distinct sets of motivations when cooperating with different types of external partner organisations, or perceive different barriers to such cooperation relationships, has not been analysed significantly in the literature to date. Motivations and barriers can indeed be multiple, mingled, heterogeneous and conflicting (Bozeman et al. 2013) and this paper has taken steps to disentangle and distinguish among them by responding to three main research questions about what spurs and restrains PSRO researchers to cooperate, the impact of academics' perceptions on their propensity to cooperate with different types of partners, and the effects of interactions between different motivations and between motivations and barriers.

\section{Coexistence of motivations and perceived barriers}

Using a factor analysis technique, we differentiated between three main motivations (advancing research, applying knowledge and accessing financial resources) and two main barriers (risk to scientific autonomy and risk to scientific credibility) affecting external cooperation. First, public sector research groups are motivated to cooperate in part by the desire to expand networks and access equipment in the interests of advancing their research. This motivation links enhanced professional recognition within disciplinary communities to opportunities presented by cooperation. Second, research groups are motivated to cooperate in order to address socio-economic needs and societal expectations by applying their knowledge. Finally, research groups are motivated to cooperate as a mechanism to access personal and group opportunities to obtain financial benefits. This is in line with findings of Perkmann et al. (2013) and D'Este and Perkmann (2011) that highlight the importance researchers attach to 
attracting resources and building social capital in support of their own academic research work.

In accordance with some previous studies of scientists' motivations to engage with industry (Lam, 2011), in our study research groups seem to be driven by a mix of both extrinsic and intrinsic rewards when participating in knowledge transfer processes with non-academic partners. On the one hand, researchers are interested in fostering their future research agendas, which can imply a wide range of interactions with external organizations for advancing research (similar to 'ribbon'), as well as seeking additional funds ('gold'), not only to obtain extra income through the commercialisation of results, but also to continue pursuing their research activities. On the other hand, the intrinsic impulse to apply knowledge and contribute to social, economic or technical problems ('puzzle') coexists as a more symbolic stimulus. This result is in line with the work of Dornbusch and Neuhäusler (2015) who suggest that the primary goal of scientists is not to apply knowledge, but to publish and to discuss their ideas within academic communities. Whereas, through cross-institutional cooperation, teams can increase their potential to contribute to technological progress.

The perceived risks to scientific autonomy we find are consistent with the "scientific norms" group of barriers proposed by Tartari and colleagues (2012). These 'orientation barriers' mainly focus on the restrictions on the disclosures and dissemination of research results (the so-called secrecy problem) and the fear to potential constraints on research priorities (the skewing problem). In line with this, research groups in our study are concerned that external cooperation could lead to interference with research programs, conflict of interests, diffusion limitations or detriment to long-term research profiles. Additionally, in our findings there is another interrelated group of barriers associated with such cooperative exchanges and the subsequent risk to scientific credibility (loss of group prestige, damage to individual careers or decline in scientific rigor). The existence of these two types of barriers would suggest the pre-eminence of traditional norms of scientific independence among PSRO research groups. However, previous experience and the development of mutual trust may nevertheless also shape views on the (potential) scientific costs of knowledge transactions with non-academic partners.

Regarding field differences, Powell and colleagues (1996) concluded that cooperation with industry is higher in life sciences, however our results are more in line with the conclusions of D'Este and Perkmann (2011) that there are higher rates of cooperation with industry among physical and engineering sciences. We also found that health and SSH research groups cooperate more with government agencies, reinforcing the argument of Olmos-Peñuela and colleagues (2014) that there are differences between STEM fields and SSH fields in cooperation activities, by establishing that such differences may also be shaped by the type of partner organization. Perception of risk to scientific autonomy and credibility also varies by scientific field.

\section{Impacts on cooperation with two types of external partners}

An apparent limitation of much of the literature on motivations to cooperate with external partners is that the focus is usually on firms alone, and we contribute to this literature by taking into consideration the type of partner organizations involved in cooperation activities and expanding the scope to include government agencies. Importantly, it is not clear whether the studies focussed on collaboration with private firms take into account the possibility that academic organizations may also be 
cooperating with other types of partner organizations. This risks concealing the additional impact that (quite possibly complementary) collaboration experiences with public sector organizations may have on a research group's motivations (and capabilities) to cooperate with firms. Successful collaborations with government agencies may drive increased motivations of research groups to collaborate with firms and vice versa.

It seems that particular motivations to cooperate are indeed associated with different types of partner organizations. Research groups that cooperate only with firms are motivated to apply knowledge and to earn financial rewards, whereas research groups that cooperate only with government agencies are motivated to advance their research. However, the majority of research groups cooperate with both firms and government agencies, with the most important motivation among these groups being the application of knowledge. The demand for knowledge, applications or consulting or other services, will be shaped by the objectives, strategies and functions associated with different types of organizations (Chompalov et al. 2002). It therefore seems logical that research groups may be motivated by particular factors in meeting these different forms of demand for cooperation. With regard to barriers, our results also showed that there are perceived barriers that can impact on the willingness of research groups to cooperate with non-academic partners. Research groups apparently consider there is a higher risk to scientific autonomy when cooperating with government, and a higher risk to scientific credibility when cooperating with firms. However, these associations are not statistically significant in our model and thus these findings cannot be considered conclusive.

\section{Interactions between multiple motivations and between motivations and barriers}

There is also an observable interaction between different types of motivations in our results, which is also dependent on the type of partner organization. Being driven to cooperate by multiple motivational factors can increase the level of cooperation, but only among those research groups cooperating with firms alone. Being highly motivated by the desire to advance research does not have any beneficial effect on the level of cooperation with firms amongst these research groups, unless the group is also highly motivated to apply knowledge and access financial resources. Research groups operating only in the industry cooperation space seem to require compound scientific and non-scientific motivations. It is important not to overstate the importance of this result, given the complicated nature of interpreting interaction effects. Nevertheless, it can be pointed out that a significant limitation of the existing literature may well lie in overlooking the interrelated nature of motivations associated with the performance of private sector cooperation. More research is needed in this respect, however our results suggest that what motivates cooperation between academic groups and industry may be more complex than is currently described in the literature.

One interpretation of this result could be that different motivations are more strongly associated with different types of demand for knowledge (Sarewitz and Pielke 2007). In terms of research activities then, the extent to which different motivations and different types of partners are closely integrated or loosely connected requires further research. This could be important to know, as knowledge spillovers between activities grounded in different motivations could be a compounding factor in estimating the benefits derived from cooperating with external partner organizations. The relationship between the characteristics of partner organizations - their goals and objectives, R\&D 
profiles and innovation strategies, for example - and the dynamics of research groups' motivations to cooperate thus seems an interesting avenue for further enquiry.

The finding that interactions between motivations are apparently dependent on the type of partner organization remained is consistent with our regression model, which showed that different motivational factors are associated with research groups that are cooperating with each of the different partner organization sub-groups. This suggests that the partner organizations, and their particular goals and objectives, also shape the interaction of motivations within a research group. Motivations to cooperate thus appear to be sensitive to societal demand - but these external demands do not have a homogenous effect on the spectrum of motivations that may drive research groups.

Methodological considerations may also be important here. The fact that such interaction effects only appear important in relation to a sub-set of research groups that cooperate only with firms (14\% of all research groups that do cooperate) may be due to the fact that the motivational items used in this study were derived from previous studies that largely investigated university-industry cooperation. Whilst in this study the type of cooperating partner was expanded to include government agencies, we were not able to also include specific motivation items that had been shown to be associated with cooperating with government. It may be that the motivations included are too narrow to fully account for research groups' interests in cooperating with government agencies, limiting the effectiveness of our analysis of interactions between motivating factors to just those research groups that cooperate only with firms. Consideration therefore needs to be given to further research that develops and pre-tests motivation items that are associated with cooperating specifically with government agencies or other types of partner organizations, to create a more solid methodological base for studies of motivations and barriers to cooperate with different types of partners.

Finally, the effect of perceived barriers on cooperation behaviour may also be related to the strength of concurrent motivations. We found that being highly motivated to advance research can reduce the effect of perceived risk to scientific autonomy, independent of the type of partner organization. This result supports the general argument of Tartari and Breschi (2012) that strong motivations can reduce the perceived importance of certain barriers to cooperation. However, being highly motivated to advance research does not reduce the perceived risk to scientific credibility for those research groups cooperating only with firms. Neither does being motivated to apply knowledge nor to access financial resources have any apparent effect on perceived barriers to cooperation in our results.

Interestingly, being motivated to advance research reduced the effect of barriers, independent of the type of partner organization. This suggest that if the research objectives of an external cooperation opportunity are relatively contiguous with a group's research objectives as a whole then motivations may overcome perceived barriers, increasing the likelihood of cooperation. This suggests a possible avenue for future research, to investigate whether relatively close 'cognitive proximity' (Boschma 2005) between PSRO research groups and external partners increases the likelihood that motivations will overcome perceptions of risks in decisions to cooperate. 


\subsection{Policy implications}

The finding that research groups' motivations are shaped by the type of cooperation partner and that research groups have different cooperation profiles suggests cooperation policies should not take a one-size-fits-all approach. A majority of research groups $(56 \%)$ cooperate with both industry and government partners, only $38 \%$ of these groups are less than ten years old, and are on average larger (11.5 FTE) than those that cooperate only with firms $(9.0 \mathrm{FTE})$ or only with government (8.8 FTE). These relatively mature and durable research groups can be considered important 'triple helix' actors within the national system of innovation, with the potential to enhance knowledge-based interactions of both scientific and societal importance. Such research groups are strongly motivated to advance their research and to apply their knowledge they are not limited by perceptions of risk to their scientific autonomy. Policy incentives for these broadly cooperating groups may thus be most effective where they support the application of groups' knowledge to address societal goals through multi-partner cooperation. It would thus seem important that policy makers develop a clear understanding of the typical path to maturity of these cooperative research groups.

Among research groups that cooperate only with firms, a majority (62\%) are more than ten years old. There are also consistent significant relationships between the control variable for age and cooperating only with firms in our regression models. In contrast, just 32 percent of research groups that cooperate only with government are more than ten years old. It may be that what is being reflected here is an outline of the evolution of research groups' external cooperation activity over time. As a research group matures and gains additional human resource capacity then cooperating with a broader range of external partners becomes more likely. From a policy perspective, measures that support the sustainability and expansion of research groups may pay dividends in terms of increasing the diversity of cooperation partners. In particular, cooperating research groups may need to mature and consolidate their experience for longer periods in order to develop the capabilities required to satisfy demands for knowledge from industry partners. Measures that consolidate research groups that are already cooperating externally can thus represent an indirect course of action that can further boost the number of cross-sector cooperation linkages between PSROs and firms.

The evidence of the effect of barriers suggests policies to promote cooperation between PSROs and other innovation system actors need to operate in a double direction: promoting knowledge application incentives (solutions to social problems, validity of research, responses to external needs); and neutralizing barriers represented by the potential for negative impact on autonomy and/or credibility (prestige, career, rigor). It is apparent that strong motivations to advance research can reduce the impact of perceived risks to scientific autonomy and this should be taken into account in designing policies that can be effective regardless of the type of cooperation partner.

It is clear that government administrations and agencies are very important counterparts to research groups in Spain, particularly SSH groups. More research is required to better understand to what extent existing cooperation with government agents is rooted in historical arrangements and patterns of interactions on one hand and responding to more recent innovation system policies and programs on the other. However, our results reinforce the importance of government as an innovation system actor and partner. This paper provides new insights into the motivations and barriers 
shaping cooperation between PSROs and industry and government partners. However, it is not able to say anything about the quality of these linkages. The evaluation of both interaction processes and associated outputs are also required to improve the quality of information that can underpin future strategies and policies.

To conclude, in this paper we sought to contribute to the existent understanding of the motivations and perceived barriers affecting researchers' cooperation with nonacademic external partners. Overall, the motivations of research groups to engage with both private and public sector non-academic organizations can be linked to multiple scientific requirements and to broader societal goals. These results point toward the willingness of academics to participate in a broad spectrum of knowledge transfer activities that ultimately can help them to keep and fulfil future research goals. In our analysis barriers to interact with both types of partners are, however, still perceived as entailing potential scientific risks. The results of our tests of interactions between motivations, and between motivations and barriers, suggest the importance of considering interaction effects. Certain motivations can counterbalance the subjective importance attributed to some barriers to cooperation. The type of non-academic partner organization can also shape PSRO researchers' cooperative behaviour when multiple motivational factors coexist.

There are limitations to the results of this study. First, although it covered four Spanish regions in a systematic and thorough way, the results may be altered if other regions were also included. Second, the study took a very open view of cooperation between PSROs and external partners. This choice was deliberate in that it was the existence of interactions and the motivations that drive them that was the focus of the study. However, if a higher threshold for cooperation had been used it may be that results may also have differed to some extent. Third, the motivations and barriers associated with activities of research groups were derived from surveys of research group leaders. Whilst group leaders are well-placed to report on the overall activities of groups, their interpretations of groups' motivations and barriers can conceivably mask some internal differences within groups. Fourth, research collaborations evolve over time (Thune and Gulbrandsen 2014), requiring a longitudinal perspective to appreciate longer-term influences on partnership dynamics. Finally, this research was conducted in the context of severe cuts and restrictions on public support for research due to rolling financial crises in Spain and abroad. A disproportionate impact of the financial crisis can be expected to fall on research groups that are less financially independent from recurrent Government investment. Under such conditions the need to obtain more funding from project or contract sources (and to bootleg this for ongoing basic research programs) may distort motivations to cooperate in the short-term and may thus have had an impact on our findings.

\section{Acknowledgments}

Funding for this project (Ref. CSO2009-07805) was provided by the Spanish National Programme of Scientific Research, Development and Innovation. A preliminary version of the manuscript was presented at the EU-SPRI 2014 Manchester Conference, University of Manchester (June, 2014). Thanks are due to session Chair Niki Vermeulen and conference delegates for the valuable comments and suggestions provided. Comments from Pablo D'Este and Elisabetta Marinelli, on an early draft of 
this paper, and Julia Olmos-Peñuela, on a later version, are also gratefully acknowledged.

\section{References}

Adams, J., Clemens, E. S., \& Orloff, A. S. (2005). Introduction: social theory, modernity and the three waves of historical sociology. In Remaking modernity: Politics, History and Sociology (pp. 1-72). Durham and London: Duke University Press.

Agrawal, A., \& Henderson, R. (2002). Putting patents in context: Exploring knowledge transfer from MIT. Management Science, 48(1), 44-60.

Aiken, L.S. \& West, S.G. (1991). Multiple regression: Testing and interpreting interactions. Newbury Park, CA: Sage.

Bekkers, R., \& Bodas Freitas, I. M. (2008). Analysing knowledge transfer channels between universities and industry: To what degree do sectors also matter? Research Policy, 37(10), 1837-1853.

Belderbos, R., Carree, M., Lokshin, B. \& Fernández Sastre, J. (2015). Inter-Temporal Patterns of R\&D Collaboration and Innovative Performance. Journal of Technology Transfer 40: 123-37.

Bercovitz, J., \& Feldman, M. (2008). Academic entrepreneurs: Organizational change at the individual level. Organization Science, 19(1), 69-89.

Bolli, T. \& Woerter, M. (2013) Competition and R\&D cooperation with universities and competitors. Journal of Technology Transfer 38: 768-787.

Boschma, R. (2005). Proximity and Innovation: A Critical Assessment. Regional Studies, 39(1), 61-74.

Bozeman, B., Fay, D., \& Slade, C. P. (2013). Research collaboration in universities and academic entrepreneurship: the-state-of-the-art. The Journal of Technology Transfer, 38(1), 1-67.

CSIC (2011). Annual Report. Downloaded from: http://documenta.wi.csic.es/alfresco/downloadpublic/direct/workspace/SpacesSt ore/08fa1688-66c9-4229-9847-f234b0bef062/MemoriaCSIC2011ing.pdf

Cunningham, J., \& Harney, B. (2006). Strategic Management of Technology Transfer: The New Challenge on Campus. year cop. 2006.

D'Este, P., \& Patel, P. (2007). University-industry linkages in the UK: What are the factors underlying the variety of interactions with industry? Research Policy, 36(9), 1295-1313, doi:10.1016/j.respol.2007.05.002.

D’Este, P., \& Perkmann, M. (2011). Why do academics engage with industry? The entrepreneurial university and individual motivations. The Journal of Technology Transfer, 36(3), 316-339.

Dasgupta, P., \& David, P. A. (1994). Toward a new economies of science. Research Policy, 23, 483-521.

Dolfsma, W., \& Verburg, R. (2008). Structure, agency and the role of values in processes of institutional change. Journal of Economic Issues, 42(4), 1031-1054.

Dornbusch, F. \& Neuhäuser, P. (2015) Composition of inventor teams and technological progress - The role of collaboration between academia and industry. Research Policy 44: 1360-1375.

Florida, R. L., \& Cohen, W. M. (1999). Engine or Infraestructure? The University Role in Economic Development. In L. M. Branscomb, F. Kodama, \& R. L. Florida (Eds.), Industrializing knowledge. . Cambridge, Ma.: MIT Press. 
Geisler, E. (1995). Industry-university technology cooperation: a theory of interorganizational relationships. Technology Analysis \& Strategic Management, 7(2), 217-229.

Geuna, A., \& Nesta, L. J. J. (2006). University patenting and its effects on academic research: The emerging European evidence. Research Policy, 35(6), 790-807.

Hall, B. H., Link, A. N., \& Scott, J. T. (2001). Barriers Inhibiting Industry from Partnering with Universities: Evidence from the Advanced Technology Program. Journal of Technology Transfer 26: 87-98.

Hall, B. H., Link, A. N., \& Scott, J. T. (2003) Universities as Research Partners. The Review of Economics and Statistics 85(2): 485-491.

INE (2011). R\&D Survey. National Statistics Institute.

Katz, J. S., \& Martin, B. R. (1997). What is research collaboration? Research Policy, 26(1), 1-18.

Lam, A. (2011). University-industry collaboration: careers and knowledge governance in hybrid organisational space. International Journal of Strategic Business Alliances, 2(1), 135-145.

Landry, R., Amara, N., \& Ouimet, M. (2007). Determinants of knowledge transfer: evidence from Canadian university researchers in natural sciences and engineering. The Journal of Technology Transfer, 32(6), 561-592.

Larédo, P., \& Mustar, P. (2001). Research and Innovation Policies in the New Global Economy: An International Comparative Analysis: Edward Elgar Publishing.

Lee, S., \& Bozeman, B. (2005). The impact of research collaboration on scientific productivity. Social Studies of Science, 35(5), 673-702.

Lee, Y. (1996). Technology transfer' and the research university: a search for the boundaries of university-industry collaboration. Research Policy, 25(6), 843863.

Leyden, D. P. \& Link, A. N. (2013). Knowledge spillovers, collective entrepreneurship, and economic growth: the role of universities. Small Business Economics 41: 797-817.

Link, A. N. \& Scott, J. T. (2005). Universities as partners in U.S. research joint ventures. Research Policy 34: 385-393.

Martin-Sempere, M. J., Rey-Rocha, J., \& Garzün-García, B. (2002). Assessing quality of domestic scientific journals in geographically oriented disciplines: scientists' judgements versus citations. Research Evaluation, 11(3), 149-154.

Martinelli, A., Meyer, M., \& von Tunzelmann, N. (2008). Becoming an entrepreneurial university? A case study of knowledge exchange relationships and faculty attitudes in a medium-sized, research-oriented university. The Journal of Technology Transfer, 33(3), 259-283.

McFadden, D. (1974). The Measurement of Urban Travel Demand. Journal of Public Economics, 3, 303-328.

Meyer-Krahmer, F., \& Schmoch, U. (1998). Science-based technologies: universityindustry interactions in four fields. Research Policy, 27(8), 835-851.

Nelson, R. (2001). Observations on the Post-Bayh-Dole Rise of Patenting at American Universities. Journal of Technology Transfer, 26, 13-19.

OECD (1999). Science, Technology and Industry Scoreboard 1999. Benchmarking Knowledge-based Economies. Paris.

Olmos-Peñuela, J., Benneworth, P. \& Castro-Martínez, E. (2013). Are 'STEM from Mars and SSH from Venus'?: Challenging disciplinary stereotypes of research's social value. Science and Public Policy, October 3: 1-17. 
Olmos-Peñuela, J., Castro Martínez, E., \& D'Este, P. (2014). Knowledge transfer activities in social sciences and humanities: Explaining the interactions of research groups withnon-academic agents. Research Policy, 43, 696-706.

Organ, D. J., \& Cunningham, J. (2011). Entrepreneurship in the Academy: The Case for a Micro-Institutional Analysis. Paper presented at the DRUID 2011 on Innovation, Strategy, and Structure - Organizations, Institutions, Systems and Regions at Copenhagen Business School, Denmark, June 15-17, 2011. Available at: http://druid8.sit.aau.dk/acc papers/ch4ofat732qeko92ggrmbha2jv61.pdf

Perkmann, M.; Tartari, V.; McKelvey, M.; Autio, E.; Broström, A.; D’Este, P.; Fini, R.; Geuna, A.; Grimaldi, R.; Hughes, A.; Krabel, S.; Kitson, M.; Llerena, P.; Lissoni, F.; Salter, A. y Sobrero, M. (2013). "Academic engagement and commercialisation: A review of the literature on university-industry relations." Research Policy, 42(2): 423-442.

Perkmann, M., \& Walsh, K. (2007). University-industry relationships and open innovation: Towards a research agenda. International Journal of Management Reviews, 9(4), 259-280.

Powell, W. W., Koput, K. W., \& Smith-Doerr, L. (1996). Interorganizational collaboration and the locus of innovation: Networks of learning in biotechnology. Administrative Science Quarterly, 116-145.

Ramos-Vielba, I. (Coord.) (2011). Una revisión de los sistemas regionales de I+D: Andalucía, Canarias, Madrid y País Vasco. . Madrid: Fundación Ideas para el Progreso. ICUE: Ideas Cooperación Universidad-Empresas.

Rokeach, M. (1979). From Individual to Institutional Values. In: Understanding Human Values, edited by M. Rokeach, pp.47-70. New York: Free Press.

Santoro, M. D., \& Gopalakrishnan, S. (2000). The institutionalization of knowledge transfer activities within industry-university collaborative ventures. Journal of Engineering and Technology Management, 17(3-4), 299-319, doi:10.1016/S0923-4748(00)00027-8.

Sarewitz, D. \& Pielke, R.A. (2007) The neglected heart of science policy: reconciling supply and demand for science. Environmental Science \& Policy 10: 5-16.

Sánchez-Barrioluengo, M. (2014). Aticulating the 'three missions' in Spanish universities. Research Policy. In press. DOI: 10.1016/j.respol.2014.06.001

Schartinger, D. (2002). Knowledge interactions between universities and industry in Austria: sectoral patterns and determinants. Research Policy, 31(3).

Shalley, C.E., Gilson, L.L. \& Blum, T.B. (2009). Interactive effects of growth need strength, work context, and job complexity on self-reported creative performance. Academy of Management Journal, 52 (3), 489-505.

Siegel, D. S., Waldman, D. A., Atwater, L. E., \& Link, A. N. (2003). Commercial knowledge transfers from universities to firms: improving the effectiveness of university-industry collaboration. The Journal of High Technology Management Research, 14(1), 111-133.

Slaughter, S., \& Rhoades, G. (1996). The emergence of a competitiveness research and development policy coalition and the commercialization of academic science and technology. Science Technology \& Human Values, 21, 303-339.

Tartari, V., \& Breschi, S. (2012). Set them free: scientists' evaluations of the benefits and costs of university-industry research collaboration. Industrial and Corporate Change, 21(5), 1117-1147. 
Tartari, V., Salter, A., \& D'Este, P. (2012). Crossing the Rubicon: exploring the factors that shape academics' perceptions of the barriers to working with industry. Cambridge Journal of Economics, 36(3), 655-677.

Teirlink, P. \& Spithoven, A. (2012) Fostering industry-science cooperation through public funding: differences between universities and public rsearch centresJournal of Technology Transfer 37: 676-695.

Thune, T. (2007). University-industry collaboration: the network embeddedness approach. Science and Public Policy, 34(3), 158-168.

Thune, T. \& Gulbrandsen, M. (2014). Dynamics of Collaboration in University-Industry Partnerships: Do Initial Conditions Explain Development Patterns? Journal of Technology Transfer 39: 977-93.

Turpin, T., \& Fernández-Esquinas, M. (2011). The policy rationale for cross-sector research collaboration and contemporary consequences. Science and Public Policy, 38(2), 82-86.

Woolgar, L. (2007). New institutional policies for university-industry links in Japan. Research Policy, 36(8), 1261-1274, doi:16/j.respol.2007.04.010. 
Annex I. Correlation matrix

\begin{tabular}{|c|c|c|c|c|c|c|c|c|c|c|}
\hline & 2 & 3 & 4 & 5 & 6 & 7 & 8 & 9 & 10 & Tolerance \\
\hline 1. Advancing research & $0.557 * *$ & $0.271^{* *}$ & $-0.164 * *$ & $-0.191^{* *}$ & 0.061 & $-0.106 * *$ & $0.071^{*}$ & 0.011 & -0.016 & 0.622 \\
\hline 2. Applying knowledge & 1 & $0.213^{* *}$ & $-0.147 * *$ & $-0.149 * *$ & $0.098^{* *}$ & -0.064 & $0.123 * *$ & 0.014 & -0.011 & 0.639 \\
\hline 3. Accessing financial resources & & 1 & -0.035 & $-0.100 * *$ & 0.015 & 0.048 & -0.003 & -0.056 & 0.011 & 0.879 \\
\hline 4. Risk to scientific autonomy & & & 1 & $0.655^{* *}$ & $-0.099 * *$ & -0.039 & -0.035 & -0.022 & -0.026 & 0.541 \\
\hline 5. Risk to scientific credibility & & & & 1 & -0.041 & -0.061 & 0.06 & -0.007 & -0.04 & 0.544 \\
\hline 6. Size (In) & & & & & 1 & $0.167 * *$ & $0.137^{* *}$ & -0.025 & $0.078^{*}$ & 0.911 \\
\hline 7. Age & & & & & & 1 & $-0.144 * *$ & $-0.088^{* *}$ & $0.102^{* *}$ & 0.911 \\
\hline 8. Scientific field & & & & & & & 1 & $0.092^{* *}$ & -0.046 & 0.892 \\
\hline 9. Region & & & & & & & & 1 & -0.033 & 0.978 \\
\hline 10. Organization & & & & & & & & & 1 & 0.968 \\
\hline
\end{tabular}

${ }^{*}$ p-value $<0.1 ; * *$ p-value $<0.05$. 
Table 1. Universities and CSIC in Spanish R\&D

\begin{tabular}{l|c|c|c}
\hline \multirow{2}{*}{ CSIC $^{\mathrm{a}}$} & \multirow{2}{*}{ Higher Education $^{\mathrm{b}}$} \\
\cline { 3 - 4 } & & Total universities & Public universities \\
\hline R\&D expenditure & $5.67 \%$ & $28.2 \%$ & $25.8 \%$ \\
\hline R\&D staff (FTE*) & $6.53 \%$ & $37.6 \%$ & $34.3 \%$ \\
\hline Researchers (FTE*) & $4.13 \%$ & $47.8 \%$ & $43.2 \%$ \\
\hline
\end{tabular}

Source: ${ }^{a}$ CSIC. Annual Report (2011). ${ }^{b}$ INE. R\&D Survey (2011)

$*$ FTE $=$ Full Time Equivalent

Table 2. Description of research group characteristics

\begin{tabular}{|c|c|c|c|}
\hline & $\begin{array}{ll}\text { Mean } & \begin{array}{l}\text { Standard } \\
\text { Deviation }\end{array} \\
\end{array}$ & $\operatorname{Max}$ & $\mathbf{N}$ \\
\hline Size & 10.24 & 68 & \\
\hline Age & More than 10 years & $56.2 \%$ & \\
\hline Organization & $\begin{array}{c}\text { Universities } \\
\text { Other (mainly CSIC) }\end{array}$ & $\begin{array}{l}74 \% \\
26 \%\end{array}$ & \\
\hline Region & $\begin{array}{l}\text { Andalusia } \\
\text { Basque Country } \\
\text { Canary Islands } \\
\text { Madrid }\end{array}$ & $\begin{array}{l}26.7 \% \\
15.5 \% \\
18.9 \% \\
38.9 \%\end{array}$ & \\
\hline Scientific fields & $\begin{array}{c}\text { Physical Sciences } \\
\text { Health } \\
\text { Social Sciences \& } \\
\text { Humanities } \\
\text { ICT \& Environmental }\end{array}$ & $\begin{array}{l}34.7 \% \\
13.2 \% \\
31.4 \% \\
20.8 \% \\
\end{array}$ & 851 \\
\hline $\begin{array}{c}\text { Partner organization } \\
\text { type }\end{array}$ & $\begin{array}{c}\text { No cooperation } \\
\text { Cooperation ONLY with } \\
\text { firms } \\
\text { Cooperation ONLY with } \\
\text { government } \\
\text { Cooperation with BOTH } \\
\text { firms \& government }\end{array}$ & $\begin{array}{l}12 \% \\
12.3 \% \\
20 \% \\
55.7 \%\end{array}$ & \\
\hline
\end{tabular}


Table 3. Factor analysis for cooperation factors (varimax rotated matrix) Panel A. Motivations

\begin{tabular}{|c|c|c|c|c|}
\hline & $\begin{array}{l}\text { Advancing } \\
\text { research }\end{array}$ & $\begin{array}{l}\text { Applying } \\
\text { Knowledge }\end{array}$ & $\begin{array}{l}\text { Accessing } \\
\text { financial } \\
\text { resources }\end{array}$ & $\begin{array}{l}\text { alpha- } \\
\text { Cronbach }\end{array}$ \\
\hline $\begin{array}{l}\text { To be up to date on research carried out } \\
\text { by other entities. }\end{array}$ & 0.769 & 0.254 & 0.021 & \multirow{5}{*}{$\alpha=0.8$} \\
\hline $\begin{array}{l}\text { To join a professional network or to } \\
\text { increase professional relationships. }\end{array}$ & 0.714 & 0.218 & 0.094 & \\
\hline $\begin{array}{l}\text { To get external views on scientific } \\
\text { research. }\end{array}$ & 0.632 & -0.18 & 0.448 & \\
\hline $\begin{array}{l}\text { To access equipment or infrastructure } \\
\text { necessary for the research group. }\end{array}$ & 0.629 & 0.453 & 0.012 & \\
\hline $\begin{array}{l}\text { To access the expertise of non-academic } \\
\text { professionals. }\end{array}$ & 0.594 & 0.302 & 0.156 & \\
\hline $\begin{array}{l}\text { To contribute to solving social, economic } \\
\text { or technical problems. }\end{array}$ & 0.129 & 0.76 & 0.086 & \multirow{3}{*}{$\alpha=0.7$} \\
\hline $\begin{array}{l}\text { To check the validity and/or practical } \\
\text { application of research. }\end{array}$ & 0.398 & 0.696 & 0.031 & \\
\hline $\begin{array}{l}\text { To keep researchers informed of the } \\
\text { needs of other agents. }\end{array}$ & 0.44 & 0.629 & 0.003 & \\
\hline $\begin{array}{l}\text { To get income as salary supplements in } \\
\text { the research group }\end{array}$ & 0.045 & 0.066 & 0.771 & \multirow{3}{*}{$\alpha=0.6$} \\
\hline To get funding for scientific research & 0.246 & -0.056 & 0.667 & \\
\hline $\begin{array}{l}\text { To try and commercialize scientific } \\
\text { results }\end{array}$ & -0.093 & 0.492 & 0.65 & \\
\hline \multicolumn{5}{|l|}{ Panel B. Barriers } \\
\hline & \multicolumn{2}{|c|}{$\begin{array}{l}\text { Risk to scientific } \\
\text { autonomy }\end{array}$} & $\begin{array}{l}\text { Risk to scientific } \\
\text { credibility }\end{array}$ & $\begin{array}{c}\text { alpha- } \\
\text { Cronbach }\end{array}$ \\
\hline Interference with research programs. & \multicolumn{2}{|l|}{0.856} & 0.149 & \multirow{4}{*}{$\alpha=0.8$} \\
\hline $\begin{array}{l}\text { Conflict of interest with the receiver of } \\
\text { the results. }\end{array}$ & \multicolumn{2}{|l|}{0.758} & 0.318 & \\
\hline $\begin{array}{l}\text { Restrictions on the dissemination of } \\
\text { research results. }\end{array}$ & \multicolumn{2}{|l|}{0.665} & 0.497 & \\
\hline Detrimental to long-term research lines. & \multicolumn{2}{|l|}{0.658} & 0.239 & \\
\hline Research group's loss of prestige. & \multicolumn{2}{|l|}{0.188} & 0.887 & \multirow{3}{*}{$\alpha=0.8$} \\
\hline $\begin{array}{l}\text { Damage to the scientific career of } \\
\text { researchers. }\end{array}$ & \multicolumn{2}{|l|}{0.274} & 0.81 & \\
\hline Decline in scientific rigor. & \multicolumn{2}{|l|}{0.448} & 0.587 & \\
\hline
\end{tabular}

Table 4. Importance of motivations and barriers by scientific field

\begin{tabular}{|c|c|c|c|c|c|c|c|}
\hline & & Total & $\begin{array}{l}\text { Physical } \\
\text { Sciences }\end{array}$ & Health & SSH & ICT\&E & $\begin{array}{c}\text { Mean } \\
\text { differences }^{\mathrm{a}}\end{array}$ \\
\hline \multirow{3}{*}{ 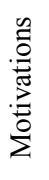 } & Advancing research & 3.01 & 2.92 & 3.09 & 3.04 & 3.04 & $0.026^{* *}$ \\
\hline & Applying knowledge & 3.14 & 3.03 & 3.08 & 3.22 & 3.24 & $0.000 * * *$ \\
\hline & $\begin{array}{l}\text { Accessing financial } \\
\text { resources. }\end{array}$ & 2.91 & 2.89 & 3.1 & 2.82 & 2.95 & $0.002 * * *$ \\
\hline \multirow{2}{*}{$\frac{\mathscr{d}}{\stackrel{D}{E}}$} & $\begin{array}{l}\text { Risk to scientific } \\
\text { autonomy. }\end{array}$ & 2.79 & 2.86 & 2.82 & 2.68 & 2.83 & $0.939 *$ \\
\hline & $\begin{array}{l}\text { Risk to scientific } \\
\text { credibility. }\end{array}$ & 2.29 & 2.25 & 2.21 & 2.37 & 2.31 & 0.575 \\
\hline
\end{tabular}


Table 5. Motivations and barriers to cooperate with non-academic agents

\begin{tabular}{|c|c|c|c|c|c|c|c|}
\hline & Model 1 & \multicolumn{3}{|c|}{ Model 2a (Multinomial regression ${ }^{\mathrm{a}}$-main effects-) } & \multicolumn{3}{|c|}{ Model 2b (Multinomial regression ${ }^{\mathrm{a}}$-three-way interactions-) } \\
\hline & \multirow{2}{*}{$\begin{array}{l}\text { Coefficient } \\
\text { (S.E.) }\end{array}$} & $\begin{array}{c}\text { Cooperation } \\
\text { ONLY with firms }\end{array}$ & $\begin{array}{c}\text { Cooperation } \\
\text { ONLY with Gov. }\end{array}$ & $\begin{array}{l}\text { Cooperation with } \\
\text { firms AND Gov. }\end{array}$ & $\begin{array}{c}\text { Cooperation ONLY } \\
\text { with firms }\end{array}$ & $\begin{array}{c}\text { Cooperation ONLY } \\
\text { with Gov. }\end{array}$ & $\begin{array}{c}\text { Cooperation with firms } \\
\text { AND Gov. }\end{array}$ \\
\hline & & $\begin{array}{l}\text { Coefficient } \\
\text { (S.E.) }\end{array}$ & $\begin{array}{l}\text { Coefficient } \\
\text { (S.E.) }\end{array}$ & $\begin{array}{l}\text { Coefficient } \\
\text { (S.E.) }\end{array}$ & $\begin{array}{l}\text { Coefficient } \\
\text { (S.E.) }\end{array}$ & $\begin{array}{l}\text { Coefficient } \\
\text { (S.E.) }\end{array}$ & $\begin{array}{l}\text { Coefficient } \\
\text { (S.E.) }\end{array}$ \\
\hline \multicolumn{8}{|l|}{ Motivations } \\
\hline Advancing research (MOT1) & $\begin{array}{c}0.283 \\
(0.311)\end{array}$ & $\begin{array}{c}0.050 \\
(0.361)\end{array}$ & $\begin{array}{l}0.883^{* *} \\
(0.345)\end{array}$ & $\begin{array}{c}0.231 \\
(0.304)\end{array}$ & $\begin{array}{c}14.149^{* *} \\
(6.760)\end{array}$ & $\begin{array}{c}3.929 \\
(3.264)\end{array}$ & $\begin{array}{l}-0.153 \\
(2.628)\end{array}$ \\
\hline Applying knowledge (MOT2) & $\begin{array}{c}0.456 \\
(0.293)\end{array}$ & $\begin{array}{l}0.656^{*} \\
(0.348)\end{array}$ & $\begin{array}{c}0.127 \\
(0.317)\end{array}$ & $\begin{array}{c}0.712 * * * \\
(0.289)\end{array}$ & $\begin{array}{l}15.451^{* * *} \\
(5.854)\end{array}$ & $\begin{array}{c}1.439 \\
(2.831)\end{array}$ & $\begin{array}{c}0.045 \\
(2.155)\end{array}$ \\
\hline $\begin{array}{l}\text { Accessing financial resources } \\
\text { (MOT3) }\end{array}$ & $\begin{array}{c}0.242 \\
(0.247)\end{array}$ & $\begin{array}{l}0.547^{*} \\
(0.291)\end{array}$ & $\begin{array}{l}-0.310 \\
(0.269)\end{array}$ & $\begin{array}{c}0.302 \\
(0.241)\end{array}$ & $\begin{array}{c}13.972 * * \\
(5.783)\end{array}$ & $\begin{array}{c}2.888 \\
(2.951)\end{array}$ & $\begin{array}{l}-2.438 \\
(2.117)\end{array}$ \\
\hline \multicolumn{8}{|l|}{ Barriers } \\
\hline $\begin{array}{l}\text { Risk to scientific autonomy } \\
\text { Risk to scientific credibility } \\
\text { Interaction terms }\end{array}$ & $\begin{array}{c}-0.027 \\
(0.273) \\
-0.488^{* *} \\
(0.236) \\
\end{array}$ & $\begin{array}{c}0.154 \\
(0.310) \\
-0.361 \\
(0.269) \\
\end{array}$ & $\begin{array}{l}-0.374 \\
(0.291) \\
-0.053 \\
(0.257) \\
\end{array}$ & $\begin{array}{l}-0.153 \\
(0.261) \\
-0.282 \\
(0.228) \\
\end{array}$ & $\begin{array}{c}0.197 \\
(0.312) \\
-0.382 \\
(0.273) \\
\end{array}$ & $\begin{array}{l}-0.353 \\
(0.293) \\
-0.052 \\
(0.258) \\
\end{array}$ & $\begin{array}{l}-0.156 \\
(0.261) \\
-0.266 \\
(0.230) \\
\end{array}$ \\
\hline \multicolumn{8}{|l|}{ Interaction terms } \\
\hline $\begin{array}{l}\text { МОТ1*МОТ2 } \\
\text { МОТ1*МОТ3 } \\
\text { МОТ2*МОТ3 } \\
\text { МОТ1*МОТ2*МОТ3 }\end{array}$ & & & & & $\begin{array}{c}-4.874^{* *} \\
(2.065) \\
-4.364^{* *} \\
(2.135) \\
-4.682^{* *} \\
(1.866) \\
1.500^{* *} \\
(0.646) \\
\end{array}$ & $\begin{array}{c}-0.860 \\
(1.049) \\
-0.654 \\
(1.216) \\
-0.016 \\
(1.093) \\
0.148 \\
(0.380)\end{array}$ & $\begin{array}{c}0.058 \\
(0.846) \\
0.749 \\
(0.974) \\
0.848 \\
(0.842) \\
-0.231 \\
(0.306) \\
\end{array}$ \\
\hline \multicolumn{8}{|l|}{ Controls } \\
\hline $\begin{array}{l}\text { Size (ln) } \\
\text { Age [Ref: <10years] } \\
\text { Organization [Ref: CSIC] }\end{array}$ & $\begin{array}{c}0.752 * * \\
(0.292) \\
0.650 \\
(0.322) \\
-0.140 \\
(0.405)\end{array}$ & $\begin{array}{c}0.359 \\
(0.334) \\
1.104 * * \\
(0.373) \\
-0.309 \\
(0.443)\end{array}$ & $\begin{array}{c}0.258 \\
(0.315) \\
0.130 \\
(0.347) \\
0.415 \\
(0.435)\end{array}$ & $\begin{array}{c}0.999^{* * *} \\
(0.284) \\
0.969^{* * *} \\
(0.311) \\
-0.035 \\
(0.378)\end{array}$ & $\begin{array}{c}0.344 \\
(0.332) \\
1.165^{* * *} \\
(0.381) \\
-0.323 \\
(0.452)\end{array}$ & $\begin{array}{c}0.301 \\
(0.317) \\
0.147 \\
(0.353) \\
0.395 \\
(0.439)\end{array}$ & $\begin{array}{c}1.042 * * * \\
(0.284) \\
0.989 * * * \\
(0.317) \\
-0.016 \\
(0.382)\end{array}$ \\
\hline Region [Ref: Basque Country] & Included & & Included & & & Included & \\
\hline Field [Ref: ICT\&E] & Included & & Included & & & Included & \\
\hline Constant & $\begin{array}{l}-0.590 \\
(1.379)\end{array}$ & $\begin{array}{l}-2.864 \\
(1.606)\end{array}$ & $\begin{array}{l}-0.229 \\
(1.482)\end{array}$ & $\begin{array}{l}-2.499 \\
(1.340)\end{array}$ & $\begin{array}{c}-45.219^{* *} \\
(18.298)\end{array}$ & $\begin{array}{l}-5.422 \\
(7.379)\end{array}$ & $\begin{array}{l}-0.084 \\
(5.142)\end{array}$ \\
\hline $\begin{array}{l}\mathrm{N} \\
\text { Log-likelihood } \\
\text { Pseudo R2 (Cragg \& Uhler's) }\end{array}$ & $\begin{array}{c}672 \\
-161.577^{* * *} \\
13.2 \%\end{array}$ & & $\begin{array}{c}672 \\
-669.98 * * * \\
17.3 \%\end{array}$ & & & $\begin{array}{c}672 \\
-660.145 * * * \\
19.7 \%\end{array}$ & \\
\hline
\end{tabular}

${ }^{*}$ p-value $<0.1 ; *$ p-value $<0.05 ; * * *$ p-value $<0.01 .{ }^{\text {a }}$ Reference category: no-cooperation 
Table 6. Motives and barriers to cooperate with non-academic agents. Interaction effects ${ }^{\mathrm{a}}$

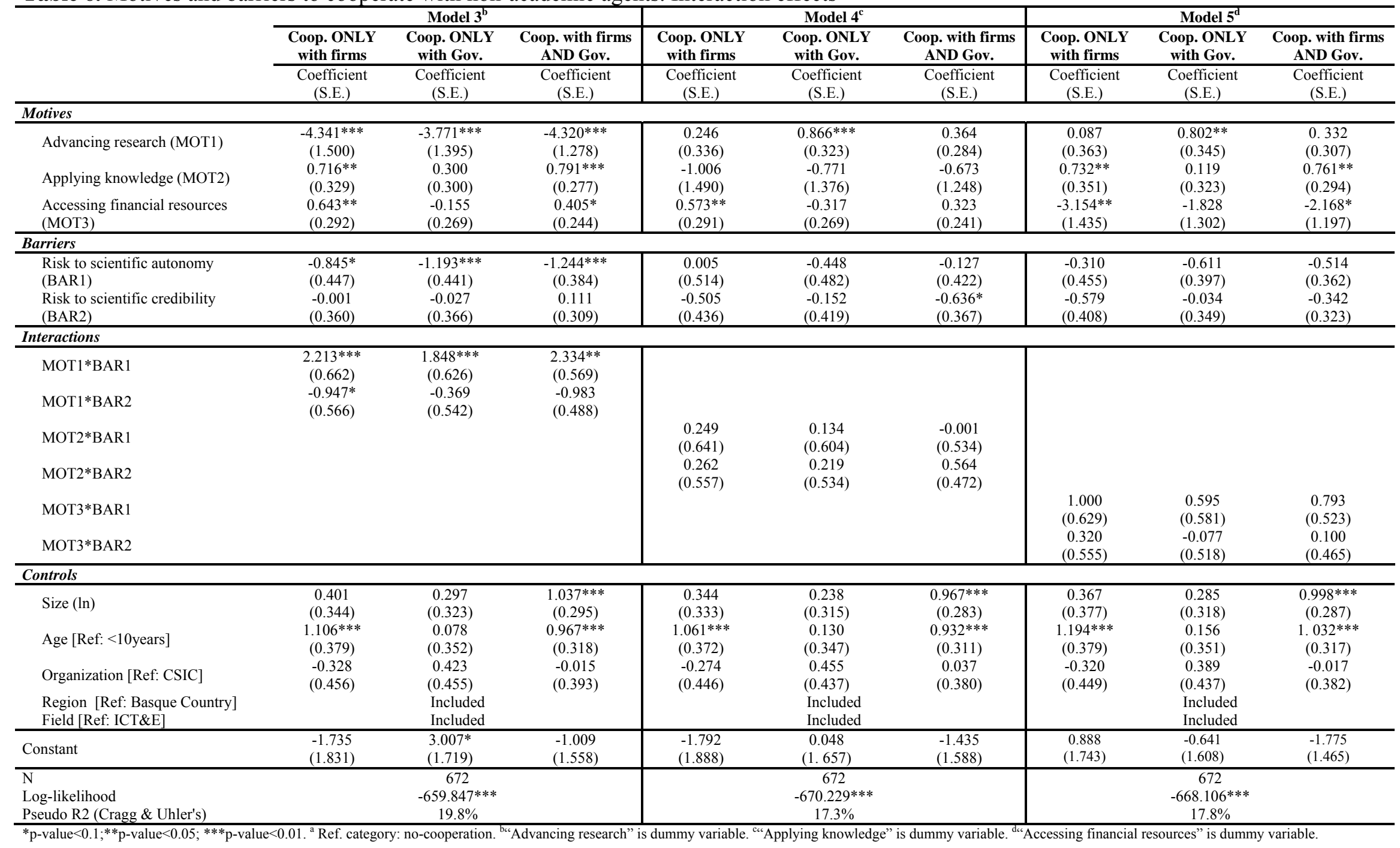


Figure 1. Total cooperation and cooperation by partner type and scientific field

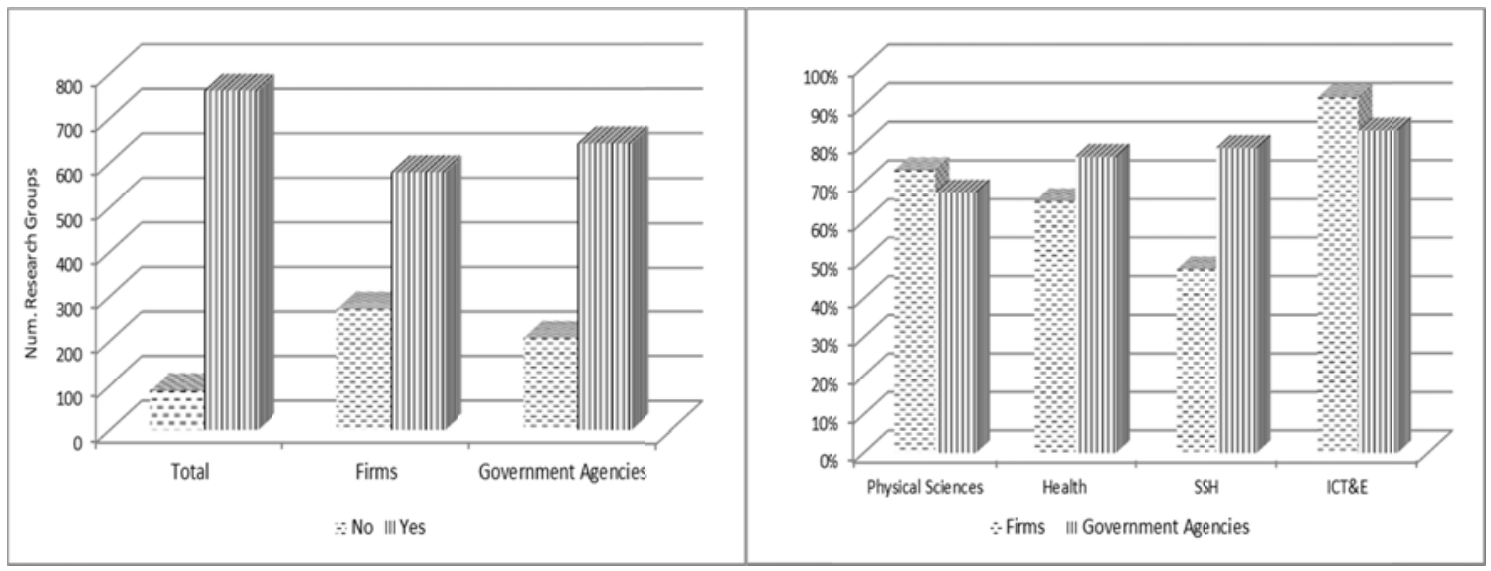

Note: $\%$ on the right figure do not sum $100 \%$ because each research group can cooperate with both firms and government agencies.

Figure 2. Three-way interaction between motivations to cooperate only with firms

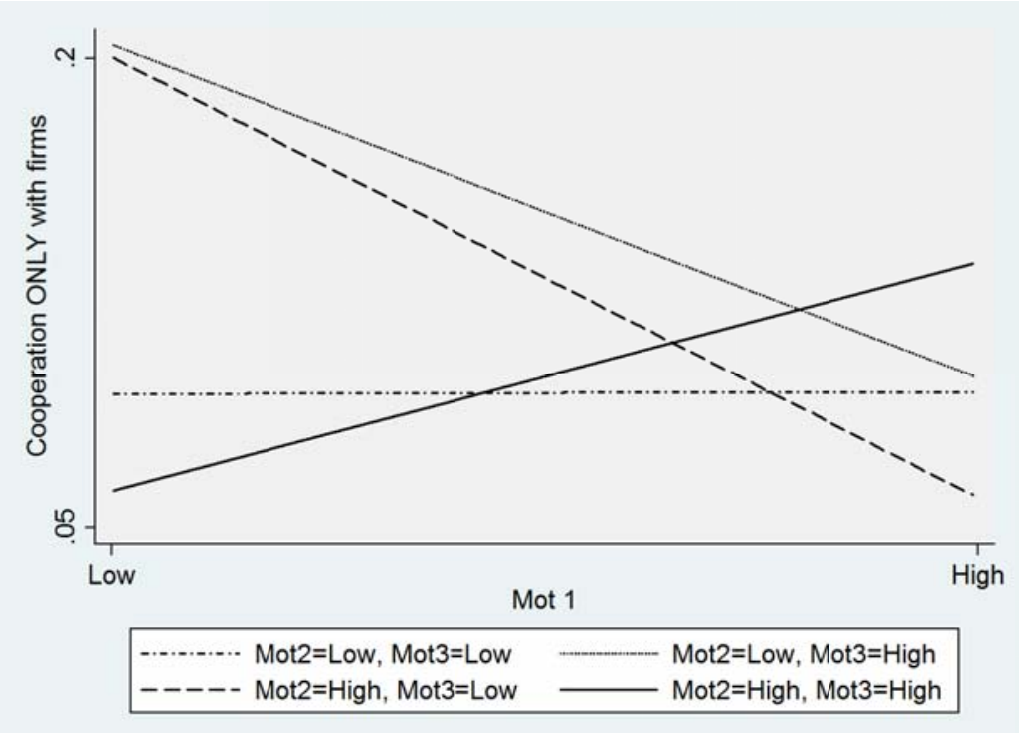

